\title{
PROJETO DE EXTENSÃO NO ENSINO TECNOLÓGICO: AMPLIANDO EXPERIÊNCIAS
}

\author{
João Victor Guinelli \\ Centro Federal de Educação Tecnológica Celso Suckow da Fonseca \\ joao.silva@cefet-rj.br \\ Carlos Eduardo Pantoja \\ Centro Federal de Educação Tecnológica Celso Suckow da Fonseca \\ pantoja@cefet-ri.br \\ Nilson Mori Lazarin \\ Centro Federal de Educação Tecnológica Celso Suckow da Fonseca \\ nilson.lazarin@cefet-rj.br
}

\begin{abstract}
Resumo
A educação, na área de Tecnologia da Informação, possui vários desafios, uma vez que lida com uma área do conhecimento dinâmica e que demanda uma contínua revisão das técnicas de ensino-aprendizagem. Além disso, os cursos técnico/tecnológicos nesta área possuem grades curriculares reduzidas a conteúdos estritamente técnicos e de baixa carga horária prática, o que acaba por não preparar o egresso para a realidade profissional do mercado. Assim, este artigo relata a experiência de um projeto de extensão que, para transformar esta realidade, ofertou treinamento específico dos estudantes envolvidos e ações técnicas de prestação de serviços gratuitos a um grupo de instituições filantrópicas. Além disso, o projeto fomentou a participação dos estudantes em feiras e congressos científicos. Entre os resultados positivos, foi possível observar que estudantesenvolvidos ampliaram suas experiênciaspor meio dos atendimentos técnicos em informática e da sua participação em vários eventos científicos.
\end{abstract}

Palavras-chave: Projeto de Extensão. Ensino. Aprendizado.

\section{EXTENSION PROJECT IN THE TECHNOLOGICAL EDUCATION: EXPANDING} EXPERIENCES

\begin{abstract}
The education, on Information Technology, field has several challenges, since it deals with a dynamic knowledge area and demands a continuous review of the techniques of teaching and learning. Furthermore, the technical/technological courses very often focus on technical disciplines instead of practical ones. For this reason, the students may not be well prepared to the real needs of the labor market. Thus, this paper presents the experience of an extension project that, to change this reality, has offered specific training for its students and a free technical assistance for philanthropic institutions. In addition, it has motivated their participation in scientific events. Among the positive results, it was observed that the students could enlarge their experience by offering computer technical support to the local community and participating of several academic events.
\end{abstract}

Keywords: Extension Project. Education. Learning.

\section{PROYECTO DE EXTENSIÓN EN EDUCACIÓN TECNOLÓGICA:EXPANSIÓN DE EXPERIENCIAS}

\section{Resumen}

La educación, en el campo de la tecnología de la información, tiene varios desafíos, una vez que se trata de un área de conocimiento dinámico que sufre constantes cambios tecnológicos y que demanda una revisión continua de las técnicas de enseñanza y aprendizaje. Adicionalmente, los cursos técnicos/tecnológicos tienen con frecuencia un plan de estudios direccionado a los contenidos estrictamente técnicos y con poco contenido práctico, lo que acaba no capacitando adecuadamente los egresados para el mercado de trabajo. Por consiguiente, este artículo describe la experiencia de un proyecto de extensión que, con el objetivo de transformar esta realidad, ha ofrecido formación específica para sus estudiantes y asistencia técnica gratuita a instituciones filantrópicas. Además, ha motivadola participación de los estudiantes 
en ferias de ciencia y congresos. Entre los resultados positivos, se observó que los estudiantes tuvieron la oportunidad de ampliar sus experiencias ofreciendo soporte técnico informático para la comunidad y de participar de varios eventos académicos.

Palabras clave: Proyecto de Extensión. Educación. Aprendizaje. 


\section{INTRODUÇÃO}

A Tecnologia da Informação (TI) desempenha papel importante na sociedade do conhecimento, influenciando diretamente as relações sociais, econômicas e culturais dos cidadãos. A educação, na área de TItem vários desafiospor se tratar de uma área dinâmica que sofre constante mudança tecnológica. O ensino neste âmbito demanda contínua revisão das técnicas de ensino-aprendizagem.

Embora o mercado de trabalho em TI seja um dos mais aquecidos, os cursos nesta área tendem a sofrer com altas taxas de evasão. Segundo Prietch e Pazeto(2010) os candidatos têm uma visão equivocada do curso, porque acreditam que este tratará sobre o uso de softwares básicos. Por este motivo, há muita desistência.Cravo (2012)apontaalguns fatores principais relacionados com a evasão em cursos técnico/tecnológicos na área de TI e destaca: o fato dos alunos não se identificarem com o curso e a falta de nivelamento da turma que acaba por prejudicar o processo de ensino-aprendizado.

Os cursos técnico/tecnológicos na área de TI visam, na maioria das vezes, uma formação rápida para inserção de mão de obra especializada no mercado de trabalho. Por este motivo, suasgrades curriculares são reduzidas a conteúdos estritamente técnicos com elevada carga teórica e com pouca ênfase em outras habilidades. Desse modo, o desenvolvimento das competências sociais, que contribuem para um exercício profissional comprometido com os valores humanos, éticos e sustentáveisé relegado para segundo plano.

Os candidatos destes cursos, por sua vez, buscam a rápida entrada no mercado e almejam altos salários. Os cursos técnico/tecnológicos não preparam o egresso para a realidade profissional do mercado pela baixa carga horária prática e pela falta de disciplinas integralizadoras de conhecimento, apesar dos seus currículos incluíremtrabalhos de conclusão de cursos e a realização de estágios obrigatórios.

Outro problema de tais cursos é que as experiências dos estudantes ficam reduzidas à sala de aula e faltam outras práticas acadêmicas. Apesar das universidades disponibilizarem programas de iniciação científica,manterem grupos e projetos de pesquisa e extensão, estimularem a divulgação da ciência e tecnologiae sediarem eventos científicos, poucos alunos têm interesse nestas atividades.

Portanto, dentro deste contexto, o objetivo deste artigo é apresentar e relatar a experiência de um projeto de extensão, chamado de Projeto Turing, que visa humanizar o processo de aprendizagem, aprimorar o conhecimento, fomentar a pesquisae apoiar a 
sustentabilidade no âmbito da formação técnica/tecnológica na área de TI. O Projeto Turing atua com base na indissociabilidade entre ensino, pesquisa e extensão por meio da oferta detreinamento específico dos estudantes envolvidos e ações técnicas de prestação de serviços gratuitos às instituições filantrópicas. Além disto, incentiva aparticipação dos estudantes em feiras e congressos científicos bem como em cursos extracurriculares específicos para complementação científica e profissional.

Dessa forma, serão apresentadas a metodologia de ensino-aprendizado e os resultados obtidos pelo projeto, que conta com aparticipação dos alunos de cursos técnico/tecnológicos em Informática do Centro Federal de Educação Tecnológica Celso Suckow da Fonseca (CEFET/RJ), Campus Nova Friburgo.

$\mathrm{O}$ artigo está dividido em quatro partes incluindo esta introdução. $\mathrm{Na}$ segunda seção é descrito o projeto de extensão, na terceira são apresentados os fatores que levaram a implantação do projeto; na quarta seção são apresentados os resultados obtidos e na quinta e última seção são apresentadas as considerações finais.

\section{O PROJETO TURING}

Nesta seção será apresentado o projeto de extensão, chamado de Projeto Turing em homenagem ao criptógrafo inglês Alan Turing, que contribuiu significativamente para o avanço da Computação. Serão apresentadas também as formas de atuação do projeto junto aos cursos e à comunidade, seus objetivos e resultados esperados.

O Projeto Turing é um projeto de extensão iniciado em 2012, no CEFET/RJ, Campus Nova Friburgo, na região serrana do Rio de Janeiro. Estepossui duas vertentes de atuação (profissional e científica) junto aos alunos do Curso Técnico em Informática e do Bacharelado em Sistemas de Informação. O objetivo do projeto ébuscar uma melhor capacitação dos alunos envolvidos nas áreas acadêmica e científica bem como técnica e profissional. Além disto, visao desenvolvimento de competências socioculturais dos participantes.

O projeto é operacionalizado num container cedido pelo Campus de Nova Friburgo e suas atividades funcionam no contraturno, buscando, dessa forma, manter os alunos por mais tempo na instituição de ensino. Os alunos podem vincular-se ao projeto das seguintes formas: a) Programa de bolsas de extensão (PBEXT), disponibilizado pela Diretoria de Extensão - DIREX / Departamento de Extensão e Assuntos Comunitários - DEAC, para alunos a partir do segundo 
período;b) Estágio interno, voluntário, disponibilizado pela Diretoria de Extensão - DIREX / Divisão de Integração Empresarial - DIEMP, contabilizando a carga horária para o cumprimento do estágio obrigatório previsto na grade do curso técnico em informática, para alunos a partir do quinto período; e c) Participaçãovoluntária, para alunos de qualquer período.

A primeira forma de atuação do projeto busca possibilitar um aperfeiçoamento profissional, através da prestação, gratuita, de assessoria técnica em informática para os discentes, funcionários e docentes do campus e também para instituições filantrópicas da região. Isto possibilita aos alunos uma vivência prática relacionada à sua formação. Para serem atendidos, os interessados devem procurar o Projeto Turing na sala de funcionamento, durante o horário de atendimento, ou através do e-mail de contato do projeto, a fim de agendarem com um dos professores orientadores o atendimento. No caso das instituições filantrópicas é possível agendar a visita de um professor orientador à instituição. O professor orientador irá analisar cada caso e encaminhar para que algum aluno efetue o atendimento, seguindo as orientações.

O aperfeiçoamento profissional ocorre pelo estimulo aos alunos para resolverem os problemas técnicos nos microcomputadores (desktops e notebooks) atendidos pelo projeto. $\mathrm{O}$ auxílio e a supervisão dos professores orientadores lhes proporcionam segurança e um aprofundamento dos conhecimentos adquiridos em sala de aula. Dessa forma,os alunos estarão mais preparados para ingressarem no mercado de trabalho, pois a experiência adquirida através da solução de problemas reais será importante para suas futuras atividades.

A segunda forma de atuação do projeto visa promover a popularização da ciência e tecnologia. Para tanto, os estudantes são incentivados aparticiparem em eventos técnicocientíficos, por meio do desenvolvimento de projetos e metodologias, apresentações de trabalhos e submissões de artigos. A participação dos alunos nos eventos científicos ocorre através da produção e apresentação de protótipos baseados em plataformas microcontroladas, artigos científicos, resumos e pôsteres nas subáreas da Ciência da Computação e Automação Industrial.

A partir da matrícula no segundo período o estudante poder participar de um projeto de pesquisa. Para tanto pode propor um projeto ou fazer parte da equipe de um projeto de pesquisa em andamento de acordo com suas afinidades e habilidades. Cada projeto de pesquisa deve conter no mínimo dois alunos e um professor orientador. Os estudantes que atuam há mais tempo no projeto auxiliam os novos entrantes. O professor responsável coordena as atividades de pesquisa do grupo. A orientação dos professores possibilita o contato inicial dos alunos com a pesquisa. Neste sentido, os estudantes devem buscar novos conhecimentos para solucionarem diversos tipos de problemas o que contribui para o aperfeiçoamento acadêmico de todos os envolvidos. 
O projeto também oferece cursos e oficinas em áreas de conhecimento não tratadas originalmente pelas grades curriculares regulares dos cursos técnico/tecnológico. Os temas dos cursos e oficinas buscam levar aos alunos as metodologias e técnicas que estão sendo utilizadas na atualidade na área da Ciência da Computação em pesquisa científica. Todos os cursos são ministrados por professores integrantes do projeto com a colaboração de alunos e geram certificados para todos os alunos participantes.

A expectativa é que os alunos envolvidosestarão mais bem preparados para ingressarem no mercado de trabalho ou para seguirem na carreira acadêmica. A experiência adquirida no desenvolvimento de protótipos para apresentação em eventos técnico-científicos ou por meio da oferta de assistência técnica e da consultoriaprestadas às instituições filantrópicas e à comunidade interna irá contribuir para a formação como profissional e cidadão.

\section{MOTIVAÇÃO}

Nesta seção será apresentada uma breve descrição das dificuldades encontradas nos cursos do Campus Nova Friburgo que motivaram a criação do Projeto Turing. Além disto, serão também comentadas as diretrizes que nortearam a concepção e desenvolvimento do projeto que visa auxiliar na formação discente.

Alguns trabalhos(PRIETCH; PAZETO, 2010; FEIJÓ, 2009) têm apresentado os problemas que afligem o ensino técnico/tecnológico, destacando-se o desinteresse e/ou a falta de identificação com o curso por parte dos alunos, a evasão escolar ou a dificuldade no aprendizado, oriundos de uma má formação de base, dentre outros. Além disso, o ensino técnico no CEFET/RJ Campus Nova Friburgo, região serrana do Rio de Janeiro, tem passado pelo problema da baixa procura (público interessado) pelo curso. Por se tratar de um campus relativamente novo, a procura pelos cursos, de todos os níveis, é menor que a oferta.

O Campus de Nova Friburgo foi inaugurado em 04 de dezembro de 2008, dentro da estrutura doPlano de Desenvolvimento da Educação (PDE) do Governo Federal. Este está localizadoem um bairro a apenas $5 \mathrm{~km}$ do centro da cidade, em imóvel cedido pelo Departamento de Estradas de Rodagem do Estado do Rio de Janeiro (DER-RJ). Atualmenteoferece um Curso Técnico em Informática, um Curso de Licenciatura em Física, um Curso de Tecnólogo em Gestão de Turismo e um Curso de Bacharel em Sistemas de Informação. 
Os idealizadores deste projeto de extensão perceberam vários fatores que afetavam o processo de ensino-aprendizagem. Entre estes se destacam: a) A desmotivação dos alunos, muitas das vezes gerada pela visão distorcida que os calouros tinham do curso, conforme retratado por Prietch e Pazeto (2010); b) A falta de perspectiva dos alunos, mesmo dos que estavam concluindo o curso técnico no segundo semestre de 2011, isto é, no sexto período. Os estudantes não se achavam prontos para enfrentar o mercado de trabalho altamente competitivo do setor de TI, também relatado por Feijó (2009); e c) A falta de envolvimento dos alunos em atividades extraclasse para desenvolvimento de competências pessoais e profissionais.

Outra característica que se percebeu nos alunos do curso técnico em informática foi o desconhecimento em relação à pesquisa e os eventos científicos que estes poderiam participar. Isto ocorria, porque a formação era estritamente voltada para o ensino, sem a perspectiva de ciência e tecnologia. Além disso, não havia uma estrutura para oferecer outras atividades para os alunos e falta de material técnico-científico para aplicação em projetos.

Diante deste cenário, buscou-se uma alternativa para a realidade encontrada em sala de aula por meio da proposta de um projeto de extensão baseado na indissociabilidadedo tripéEnsino-Pesquisa-Extensão. Este foi elaborado de forma a oferecer: a) Ensino: auxilia a solidificação do conhecimento adquirido em sala e o aperfeiçoamento profissional através da solução de casos/problemas reais; b) Extensão: presta assessoria técnica, de forma gratuita, à comunidade do campus e instituições filantrópicas e promove cursos de extensão (cursos e oficinas) para os alunos do campus; e c) Pesquisa: incentiva a participação em eventos técnicocientíficos, através do desenvolvimento de protótipos, metodologiase a confecção de artigos científicos.

A idealização do projeto foi norteada pelamelhoria na integraçãocom a comunidade através da aplicaçãodos conhecimentospor meio da prática social e ampliação dos horizontes acadêmicos dos alunos com a popularização da ciência e tecnologia.

\section{RESULTADOS OBTIDOS}

Nesta seção serão apresentados os resultados apurados pelo Projeto Turing em dois anos de atuação junto aos cursos Técnicos e de Graduação do CEFET/RJ Campus Nova Friburgo. Os resultados são apresentados baseados nas duas formas de atuação do projeto (técnicaprofissional e científica-tecnológica). 
Entre abril de 2012 até janeiro de 2014 dentro da abordagem voltada para o aperfeiçoamento profissional foram realizados cento e noventaatendimentos técnicos em informática em prol da comunidade interna do CEFET/RJ e de algumas instituições filantrópicas. Os atendimentos em informática, apresentados na Ilustração 1 estão divididos nas seguintes categorias: a) Preventiva: atendimentos referentes à manutenção preventiva de microcomputadores, por meio dos quais sãorealizadas a desmontagem, limpeza, instalação de atualizações de segurança de softwares, testes de funcionamento e desempenho; b) Software: atendimentos referentes à instalação ou atualização de softwares (aplicativos de escritório, navegadores de internet, antivírus, etc.); c) Hardware: atendimentos referentes à correção de problemas de travamento ou inicialização (remoção de vírus, limpeza, substituição de componentes); e d) Infraestrutura: atendimentos referentes à montagem de laboratórios e infraestrutura de redes.

\section{Quantitativo de Atendimentos Comunitários no Período entre 2012-2014 Realizados pelo Projeto Turing}

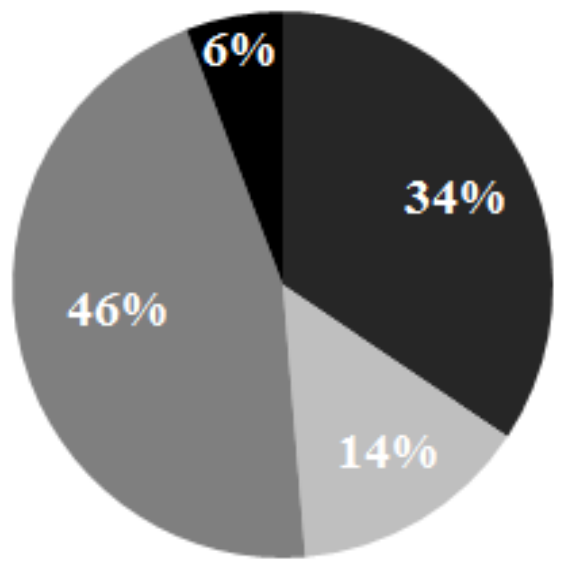

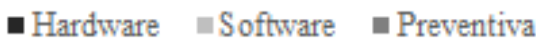

-Infraestrutura

Ilustração 1 - Quantitativo de Atendimentos Comunitários no Período entre 2012 e 2014 realizados pelo Projeto Turing. Fonte: os autores, 2015.

Com relação à abordagem científica e tecnológica, os estudantes participaram em diversas feiras estaduais e nacionais, mostras nacionais, congressos e conferências nacionais e internacionaisdurante o período entre 2012 e 2015. Os eventos científicos permitiram uma troca de conhecimento com outras universidades e institutos. Isto possibilitou diversas parcerias para enriquecimento não só técnico, mas também sociocultural. 
Os eventos técnico-científicos incluem: COBENGE - Congresso Brasileiro de Educação em Engenharia; EXPOTEC RIO - Exposição da Produção em Tecnologia de Alunos De Cursos de Educação Profissional Técnica de Nível Médio do Estado do Rio de Janeiro; FEBRAT - Feira Brasileira de Ciência, Tecnologia e Inovação dos Colégios de Aplicação e Escolas Técnicas das Redes Pública e Privada; FECTI - Feira Estadual de Ciência, Tecnologia e Inovação do Estado do Rio de Janeiro; MNR - Mostra Nacional de Robótica; SULCOMP - Congresso Sul-Brasileiro de Computação; ERBD - Escola Regional de Banco de Dados; SBSI - Simpósio Brasileiro de Sistemas de Informação; WESAAC - Workshop-Escola de Sistemas de Agentes, seus Ambientes e Aplicações; COTB - Computer On The Beach; ICSCT - InternationalConferenceon Software andComputing Technology; e ICAART- InternationalConferenceonAgentsand Artificial Intelligence.

$\mathrm{Na}$ Ilustração 2 é possível observar a distribuição da produção acadêmica. A produção está dividida em apresentação de trabalhos, contabilizados como eventos de nível técnico, feiras e mostras, além de apresentações em seminários e eventos sem ISBN ou ISSN; trabalhos completos em anais de congressos nacionais e internacionais bem como em revistas e periódicos.

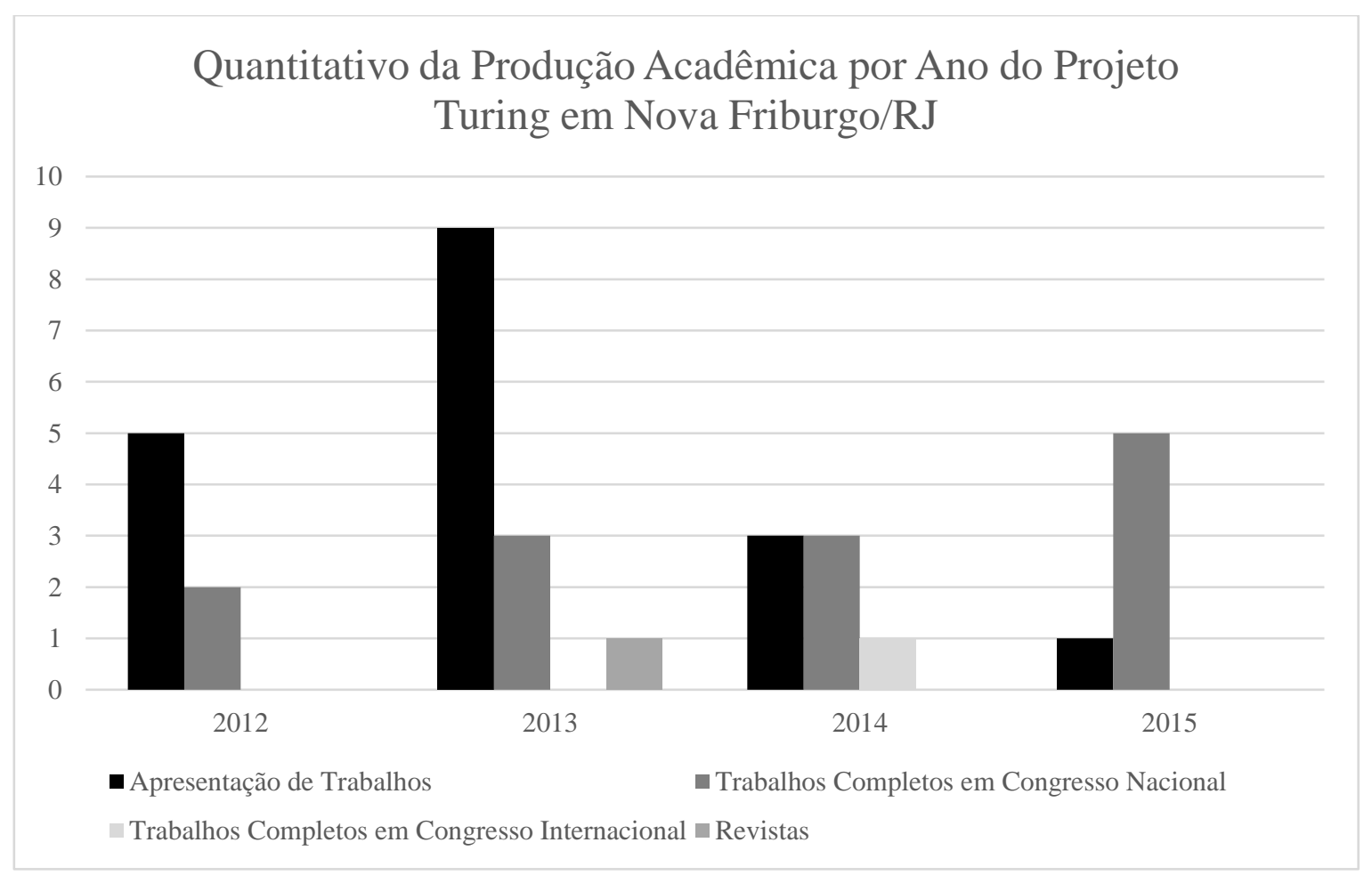

Ilustração 2 - O quantitativo da produção acadêmica entre 2012 e 2015 realizadas pelo Projeto Turing. Fonte: os autores, 2015.

Por meio do projeto percebe-se que este colabora parainiciação dos alunos envolvidos durante esse período, na área acadêmica através da redução da apresentação de trabalhos que não 
possuem anais com ISBN ou ISSN, para um aumento na produção de trabalhos completos apresentados em eventos reconhecidos (inclusive com classificação QUALIS para conferências na área da Ciência da Computação). Proporcionalmente, há um crescimento na participação dos alunos do projeto em congressos durante o período, além do início da participação em eventos internacionais e da publicação emperiódicos, explicitando a maturidade dos projetos desenvolvidos pelo aluno e o comprometimento dos idealizadores do projeto em proporcionar uma vivência acadêmica nos primeiros anos do ensino tecnológico. A Ilustração 3 mostra a proporção de produção acadêmica por ano.

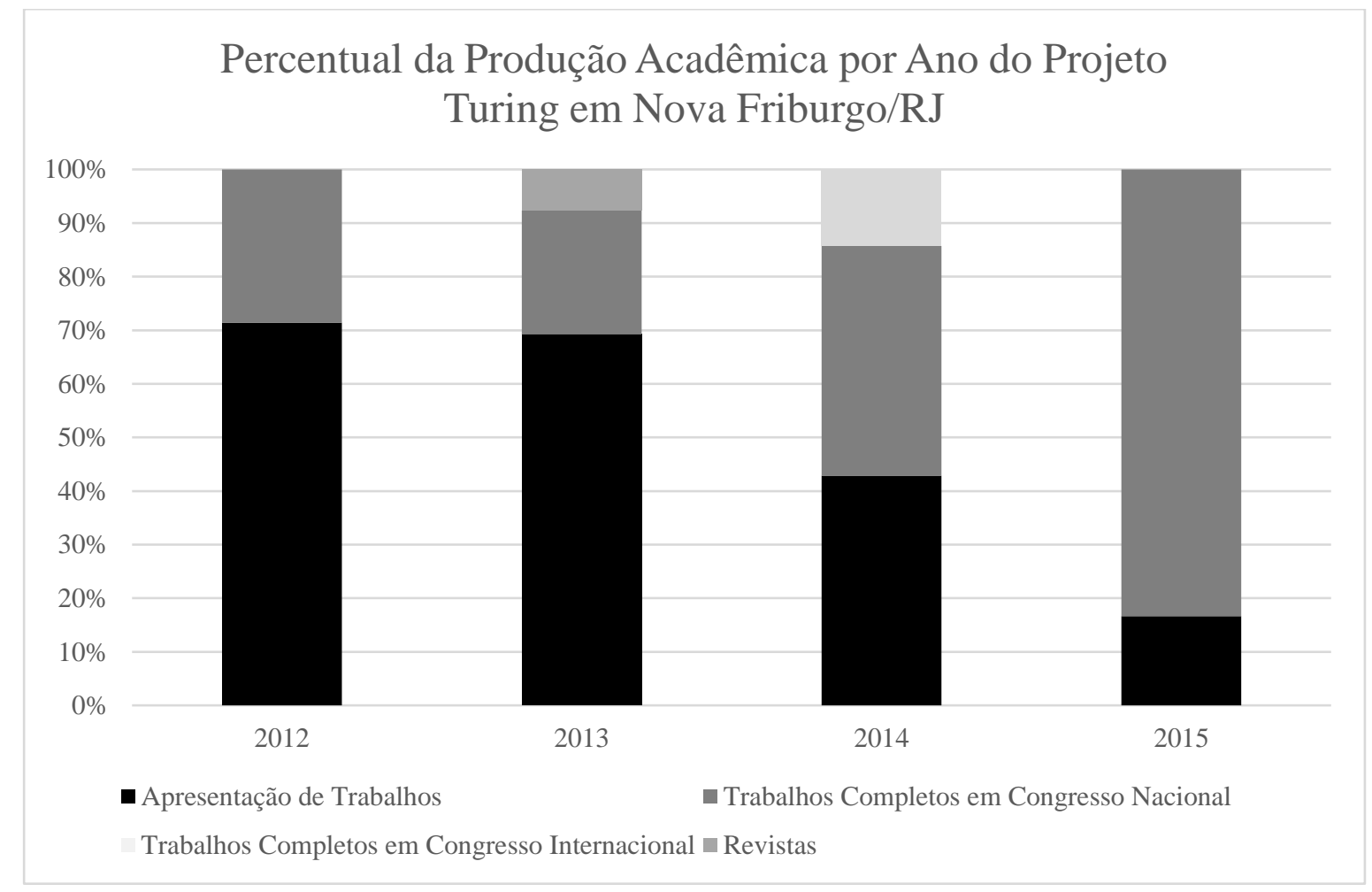

Ilustração 3 - Percentual da produção acadêmica do Projeto Turing entre 2012 e 2015. Fonte: os autores, 2015.

No projeto o estudante que têm um trabalho aceito em eventosé incentivado à apresentálos. Dessa forma, o aluno aperfeiçoasuas habilidades de comunicaçãoe técnico-científicas que são inerentes a um projeto de pesquisa. Os projetos de pesquisa tiveram ao longo desse período onze alunos envolvidos diretamente em desenvolvimento de protótipo, metodologias e ferramentas de software, que possibilitaram a redação de artigos e a realização da apresentação dos projetos pelos próprios alunos. Durante este mesmo período, houve o aumento no número de participantes do projeto. O número subiu de seis para vinte e três pessoas envolvidas e destas dezoito são estudantes. Além disso, o Projeto Turing foi estendido para mais duas unidades (Nova Iguaçu e 
Projeto de extensão no ensino tecnológico: ampliando experiências

Maria da Graça). A Ilustração 4 exibe a distribuição dos envolvidos no Projeto Turing entre 2012 e 2015.

Entre os temas na área de Ciência da Computação trabalhados pelos projetos de pesquisa podem-se destacar: Arquitetura Orientada a Modelos; Geração de Codificação Automática; Geradores de Números Pseudo-Aleatórios; Inteligência Artificial e Sistemas Multi-Agentes; Desenvolvimento de Protótipo Utilizando Microcontroladores; e Cinemática de Corpos.

Destaca-se que no período de funcionamento do Projeto Turing, os alunos conseguiram: 1 medalha de bronze na categoria informática (EXPOTEC RIO 2012), 1 medalha de bronze na categoria eletrônica (EXPOTEC RIO 2013), 1 medalha de ouro e troféu na categoria informática (EXPOTEC RIO 2013), 1 bolsa Iniciação Científica Junior - CNPQ (MNR 2012), 1 menção honrosa em Ciência da Computação (EXPOTEC RIO 2014).

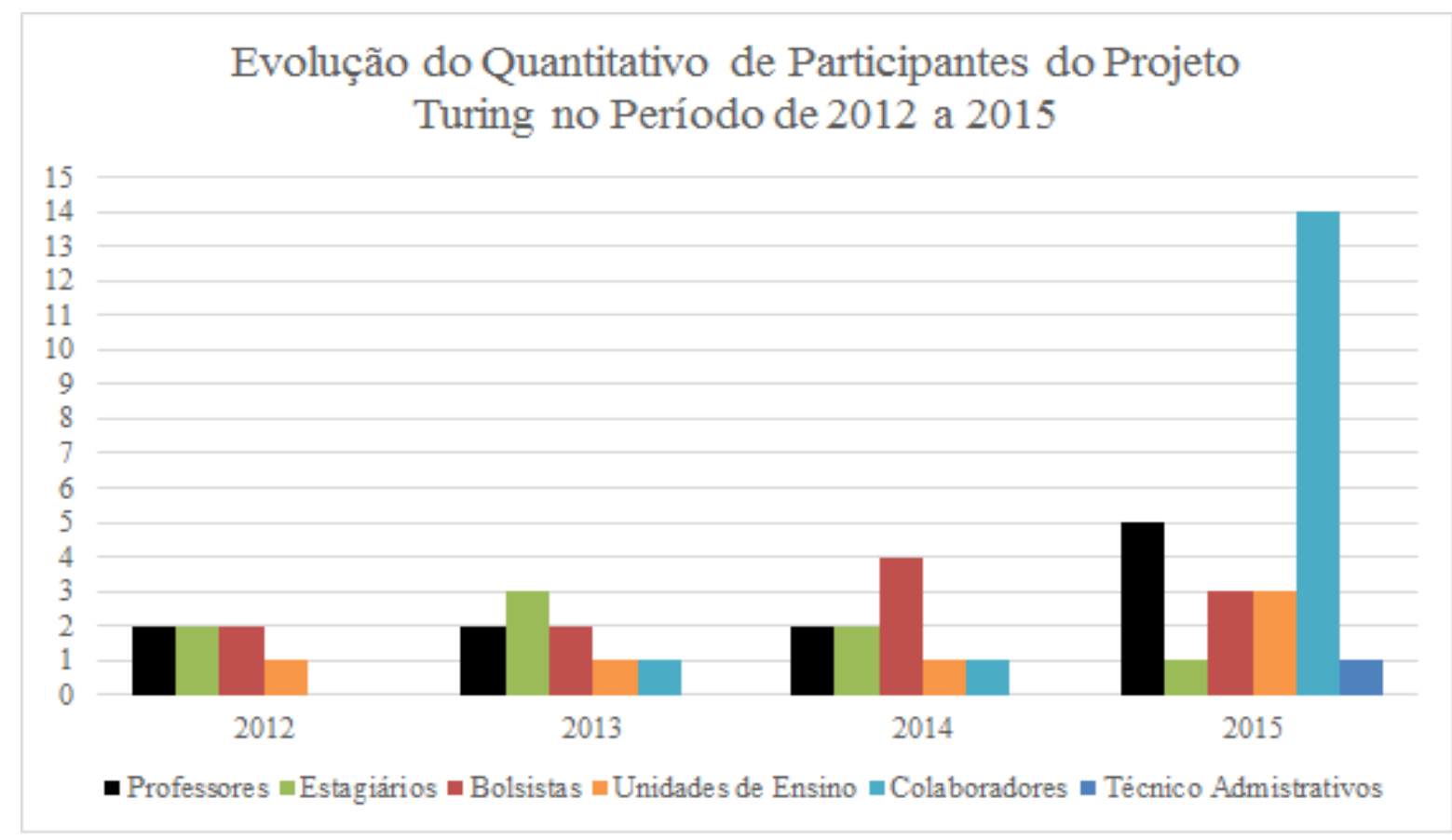

Ilustração 4 - A evolução dos participantes do projeto desde 2012. Fonte: os autores, 2015.

O Projeto Turing também realizou a recuperação de diversos computadores que foram doados às diversas instituições filantrópicas da região serrana do Rio de Janeiro. Entre os equipamentos doados incluem-se: 6 computadores para a Pestalozzi de Nova Friburgo; 6 computadores para o Lar-abrigo Amor a Jesus (LAJE); e 8 computadores para Legião da Boa Vontade (LBV). O projeto promoveu a organização de novos laboratórios e fez a reciclagem de $34,879 \mathrm{Kg}$ de metal e 30,453 Kg de plástico. Todo material que é descartado é pesado em uma 
balança de precisão digital de 1 g.Na Ilustração 5é apresentado um dos laboratórios montados durante o projeto.

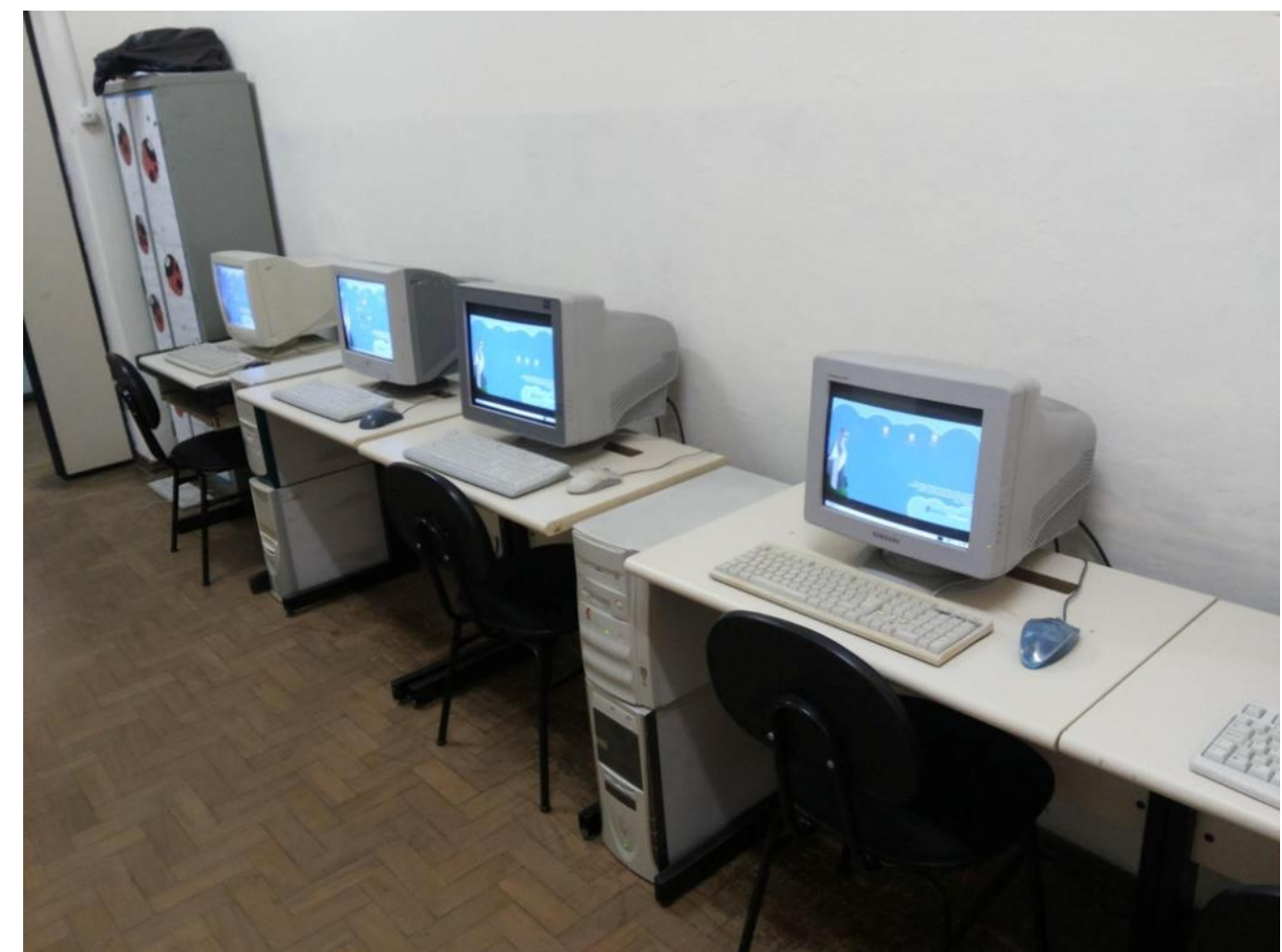

Ilustração 5 - Laboratóriomontadoa partir das ações do Projeto Turing. Fonte: os autores, 2015.

\section{CONSIDERAÇÕES FINAIS}

O CEFET/RJ tem por finalidade oferecer a educação tecnológica, nos diferentes níveis e modalidades de ensino, tendo como missão institucional promover a educação mediante atividades de ensino, pesquisa e extensão que propiciem, de modo reflexivo e crítico, a interação com a sociedade, a formação integral (humanística, científica e tecnológica, ética, política e social) de profissionais capazes de contribuir para o desenvolvimento cultural, tecnológico e econômico dessa mesma sociedade (DIGES - CEFET/RJ, 2010).

Embora a missão institucional do CEFET/RJ esteja bem definida e busca a formação ampla do aluno, integrando ensino, pesquisa e extensão, no Campus Nova Friburgo, até o primeiro semestre de 2012 (três anos após sua inauguração), não havia cursos nem projetos de extensão voltados para a formação integral dos alunos do ensino técnico/tecnológico na área de TI. Dentro deste cenário, surgiu o Projeto Turing, que se baseiana indissociabilidade entre 
Ensino, Pesquisa e Extensão. O projeto visou auxiliar a solidificação do conhecimento adquirido em sala de aula; contribuir com o aperfeiçoamento profissional através da solução de casos/problemas reais, prestar assessoria técnica gratuita à comunidade do campus e ainstituições filantrópicas, promover cursos de extensão para os alunos do campus e incentivar a participação dos mesmos em eventos técnico-científicos.

Como resultado, o projeto conseguiu ao longo de seusdois primeiros anos de atuação, propiciar aos alunos participantes uma maior experiência prática através da solução de casos reais por meio da oferta desuporte técnico na área de informática. Além disso, prestou assessoria técnica às instituições filantrópicas, promovendo o engajamento dos estudantes numa atividade com cunho social.

$\mathrm{Na}$ área científica o projeto ampliou a experiência acadêmica dos estudantes por meio da sua participação em feiras de ciências regionais e nacionais eda apresentação de diversos trabalhos em eventos científicos nas modalidades artigo completo, resumo e pôsterem nível técnico e de graduação. Através da submissão de trabalhos científicos a determinados eventos, os estudantessocializam resultados do projeto. Este aspecto do projeto reforça a área de pesquisa no âmbito institucional e na formação acadêmica dos discentes, contribuindo para a popularização da ciência e tecnologia.

Pode-se perceber também que, através das ações do projeto, houve um maior interesse e envolvimento dos estudantes no processo de ensino-aprendizagem, na geração de conhecimento e nas questões sociais e ambientais. O envolvimento refletiu indiretamente na melhora da visibilidade dos cursos técnico/tecnológicos, da área de TI, no Campus Nova Friburgo. Isto ocorreu devido aos resultados obtidos pelos alunos o que atraiu novos interessados. A melhoria nos índices de entrada e permanência nos cursos é importante para combater as altas taxas de evasão que afligem os cursos de tecnologia de modo geral.

Como trabalhos futuros, o Projeto Turing visa aumentar as ações de captação e recuperação de computadores antigos e em desuso para doá-los às instituições filantrópicas. Desta forma, objetiva contribuir para a difusão da área de tecnologia na região serrana do Rio de Janeiro.

O projeto também visa começar uma linha de desenvolvimento de jogos com a finalidade de proporcionar aos envolvidos conhecimento e habilidades técnicas para estarem aptos a atuar nesse novo nicho de mercado. Além disto, pretende incentivara criação de jogos livres e socioeducativos. Para os próximos anos a proposta é oferecer um maior número de cursos e oficinas aos alunos do Campus, a fim de ampliar o número de participantes. Atualmente devido à 
Projeto de extensão no ensino tecnológico: ampliando experiências

alta carga horária dos docentes envolvidos e a falta de colaboradores tecnicamente capacitados a oferta de novas atividades e vagas ainda é limitada.

\section{REFERÊNCIAS}

CRAVO, Ana Cristina (2012). Análise das causas da evasão escolar do curso técnico de informática em uma faculdade de tecnologia de Florianópolis. Revista Gestão Universitária na América Latina-GUAL, 5(2):238-250.

DIGES - CEFET/RJ (2010). Plano de desenvolvimento institucional - PDI 2010/2014 / CEFET/RJ.

FEIJÓ, Alexandre Araújo (2009). Fatores Determinantes da Motivação/Desmotivação de Alunos do curso Técnico em informática do Colégio Agrícola de Camboriú-UFSC. Dissertação de mestrado, Decanato de Pesquisa e Pós-Graduação Instituto de Agronomia Programa de Pós Graduação em Educação Agrícola, Seropédica-RJ.

PRIETCH, Soraia Silva; PAZETO, Tatiana Annoni (2010). Estudo sobre a evasão em um curso de licenciatura em informática e considerações para melhorias. WEIBASE, Maceió. 